\title{
INSTABILITY, FREQUENCY AND VOLTAGE IN MANAUS
}

\author{
Talitha do Nascimento Brito ${ }^{1}$, Manoel Henrique Reis Nascimento ${ }^{2}$ and Francisco Rodrigues Maia ${ }^{3}$
}

\author{
${ }^{1}$ Foundation Center for Analysis, Research and Technological Innovation - FUCAPI. Manaus-Amazonas, Brazil. \\ ${ }^{2}$ Galileo Institute of Technology and Education of the Amazon - ITEGAM. Manaus-Amazonas, Brazil. \\ ${ }^{3}$ Amazonas State University - UEA. Manaus-Amazonas, Brazil.
}

Email: talitha.brito@ hotmail.com, hreys@bol.com.br, fcomaia@ gmail.com

Received: Nov $27^{\text {th }}, 2019$

Accepted: Nov 29th 2019

Published: February $10^{\text {th }}, 2020$

Copyright (C2016 by authors and Galileo Institute of Technology and Education of the Amazon (ITEGAM).

This work is licensed under the Creative Commons Attribution International License (CC BY 4.0).

https://creativecommons.org/licen $\underline{\text { ses/by/4.0/ }}$

\begin{abstract}
The article describes the system instability, frequency and voltage in Manaus. Electrical systems are relevant to the functioning of cities and are constantly evolving to meet growing demands. The deregulation of the sector and the continuous incorporation of new equipment technologies make the system's operation complex. Therefore, it is necessary to improve the methods and instruments for monitoring and controlling the operation of the system in real time. Several technologies appear every year, but in Brazil there is the Automatic Generation Control (GAG) and supervisory control of the system, which aims to control the generation in plants in order to meet the goals determined by the System Operator. Ensuring that the frequency remains constant and in a range close to its nominal value. It also has the power flow control function in the interconnection lines. Increasing demand for electricity today means that electric power systems operate near the limit. The lack of policies appropriate to the reality of the sector and the economic order of the country aggravate the problem of power generation with regard to frequency and voltage stability. The objective of this paper is to evaluate the performance and identify the most appropriate strategy of Load-Frequency and Voltage Control for the case of the Manaus system, when the Network Operation topology changes.
\end{abstract}

Keywords: Electrical Systems, Instability, Voltage.

\section{INTRODUCTION}

From the installation of the first generators and transmission lines to the present day, electrical systems have become more interconnected and extensive, spanning large areas, and meeting increasing demands. The intensification of this process, together with factors such as the deregulation of the sector and the continuous incorporation of new equipment technologies, have greatly increased the operational complexity of electric power systems. Then comes the need for constant improvement of methods and instruments dedicated to monitoring and controlling their operation in real time [1].

Among the new technologies that have been proposed, have added the functions of Automatic Generation Control (CAG) and Supervisory System Control (CSS) [2]. The purpose of the $\mathrm{CAG}$ is to control the generation of the main plants, according to the targets set by the operator, in order to keep the frequency approximately constant and within a range close to its nominal value, as well as to control the power flow in the power lines. interconnection [3].

These characteristics meet current technological needs and enhance the development of new paradigms for system supervision and control in real time. Voltage stability can be defined as the ability of the power system to maintain voltages at acceptable levels using the Automatic Voltage Regulator (AVR) both under normal operating conditions and after a disturbance. The main factor causing voltage instability is the inability of the electrical power system to meet reactive demand after a disturbance [4].

Electric power systems are operating ever closer to their limits. This is because the increase in the demand for electricity and the complexity of such systems has not been accompanied by investments, whether for economic, environmental or political reasons. Such factors have contributed to the occurrence of several problems related to frequency and voltage stability [5].

This paper aims to evaluate the performance and identify the most appropriate strategy of Load-Frequency and Voltage 
Control for the case of the Manaus System, when the Network Operation topology changes.

\section{MATERIALS AND METHODS}

The present work presents a study about the model used for the charge-frequency and voltage control system in electric power systems specifically for the case of the Manaus-Amazonas system.

First the characterization of the generator-load system was made through the use of the DIgSILENT PowerFactor tool used in the engineering field for power system analysis and the fundamental components that are involved in the generation and control of the system.

A transient and steady state analysis was performed so that it was possible to show how the system components behave individually and also how they act together.

To prove the analysis and better understand it, simulations were performed in response to a step load variation.

The methodology for conducting the load-frequency rejection and reactive power tests consisted of field records and the supervisory system of electrical quantities such as voltage, frequency, power, in the generating units, during electrical disturbances and after impact or slow variation of active power. or reactive in the Manaus Electric System.

In each test were recorded simultaneously, in two generating units of the Plant, the following quantities: Frequency \& Time; Terminal Voltage \& Time; Active Power \& Time; Reactive Power \& Time; Field Voltage \& Time \& Actuator Position \& Time.

Regarding the steady state voltage values, the Basic Network performance standard at the connection points must meet the requirements of ANEEL Resolution 505/2001. According to Article 4 of the referred resolution, the service voltage will be classified according to the ranges of reading voltage variation, according to the range below, and from January 2005 the voltage to be contracted by the concessionaires from The National System Operator (ONS) was the nominal voltage of the connection point [6].

In addition to the tests performed, some references from similar research works were also considered, such as: Power System Frequency Implementation and Control - Federal University of Rio de Janeiro by Rodrigo Ribeiro Ferreira. "(2009), Basic Aspects of Load-Frequency Control in Power Systems Faculty of Technology of Brasília by Frederico Alves Matos de Lima." (2008), Santa Rosa, Arthur da Silva. Influence of NonRepresentation of Slow Control Devices on Voltage Safety Analyzes. Dissertation by M. Sc., Federal University of Itajubá, Itajubá, MG, 2007. Ehrensperger, Juliana Gubert. "Synchronized phasor measurement systems: state-of-the-art analysis and applications in power system monitoring." (2004). In the English and Portuguese languages, in order to provide greater reliability in the data to be used, as well as internal studies of Eletrobrás in the Manaus unit which data were collected from a supervisory software called Wartsila-WOIS Online Monitoring System over a period of 90 days, imported and grouped in applications such as Word and Excel, for analysis and data processing, through a system analyzer, compared to the goals set by ONS, in order to keep the frequency and voltage approximately constant and within a range close to its nominal value.
III. FREQUENCY AND VOLTAGE INSTABILITY IN THE MANAUS SYSTEM

\section{1 FREQUENCY INSTAB ILITY}

To understand why the frequency can go out of $60 \mathrm{HZ}$, just look at the mathematical formula of the dynamic equation for a disturbing system [7].

\section{Dynamic Equation Frequency 1}

a)

$$
\frac{d w}{d t}=\frac{w}{2 H} *(P m-P e)
$$

At where:

$\mathrm{dw}=$ Angular velocity derivative in radian per second $\mathrm{dt}=$ Derived as a function of time in seconds. in seconds.

$\mathrm{dw} / \mathrm{dt}=$ Angular velocity derivative as a function of time

$2 \mathrm{H}=$ Inertia constant in seconds.

$\mathrm{w}=$ Angular Speed Machine.

$\mathrm{Pm}=$ Mechanical power imposed by the Primary

$\mathrm{Pe}=$ Electrical power requested by the system.

It is found that $\mathrm{dw} / \mathrm{dt}$ is the angular velocity derivative as a function of time, ie, in steady state where $\mathrm{Pm}=\mathrm{Pe}$ the derivative is zero, ie the frequency is constant, where ( $w=2 . P i . f)$, ie the frequency is directly proportional to Machine speed and inversely proportional to Inertia.

"Big" machines with heavy axles have a higher Inertia, which consequently has a smaller speed variation ( $\mathrm{dw} / \mathrm{dt}$ ). Therefore, in order to have an imbalance, a variation of $\mathrm{Pm}$ or $\mathrm{Pe}$ is necessary. In the increase of load $(\mathrm{Pe})$ the derivative is negative, and there is a decrease in speed and frequency as well [8].

In load relief $(\mathrm{Pe})$ the derivative is positive, and there is an increase in velocity and therefore the frequency tends to rise.

ANEEL, through the National Electric System Operator [9], determines in accordance with Module 3.6 (Grid Procedures) that the frequency does not vary above $+-0.1 \mathrm{~Hz}$. The main control systems acting on the synchronous generator are three:

1. primary speed control;

2. Supplemental load-frequency control, or Automatic Generation Control;

3. Control of Excitation.

The primary speed control, which is local, basically monitors the turbine-generator set shaft speed and controls the mechanical torque of the turbine to make the electrical power generated by the unit adapt to load variations. The time constants of the primary control are of the order of a few seconds [9].

Since actuation of the primary control usually results in frequency deviations, another control system must be relied upon to reset the frequency to its nominal value. This system is called supplementary control (or Automatic Generation Control) which, in the case of interconnected systems, also has the task of keeping the power exchange between neighboring utilities as close as possible to the previously programmed values. It is a centralized control system, executed in the operations center of companies, and whose time constants are of the order of minutes.

Manaus operates with a Window of $+-0.5 \mathrm{~Hz}$, due to the fluctuation of the system due to instability in the External System, which causes [10]:

- Increased fuel consumption; 

actuator;

- Increased wear on Governor fuel injection racks and

- Increased wear on injection pumps; and

- Instability at Machine Operating Speed.

Each time the frequency varies by $+-0.5 \mathrm{~Hz}(60+-0.5$ $\mathrm{Hz}$ ), the Woodward-723 Speed Hydraulic Actuator changes from KW control to Speed Droop Mode in 100 milliseconds and returns to Operation mode. MW control within 15 seconds, as shown in the graph of figures 1 and 2 below, shows the graph of the frequency range threshold window.

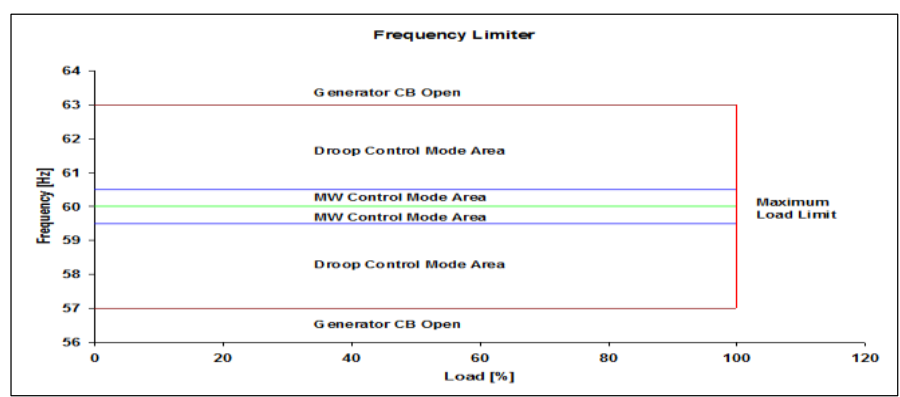

Figure 1: Graph of indication of frequency variation limits (Droop window).

Source: [11].

The parameters configured in the electronic regulator are:

a) Maximum Load Limit: $16.15 \mathrm{MW}$;

b) MW Control Override: 60.5 / $59.5 \mathrm{~Hz}$; and

c) Override Reset Time: 15 seconds (if inside $60+-0.5 \mathrm{~Hz}$ window).

As mentioned above, Figure 2 shows the graph shows the load / frequency response:

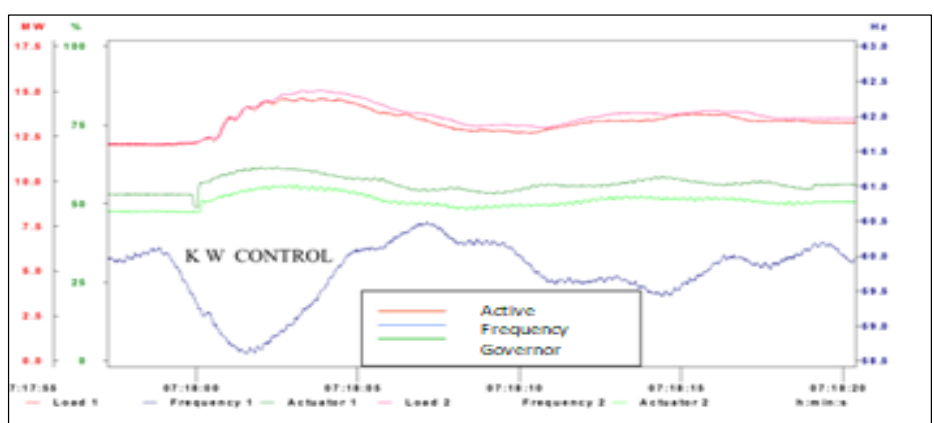

Figure 2: Load / Frequency Response Graph of droop window machine.

Source: [11].

Figure 3 shows the chart of the Control chart of the current system frequency situation behavior, with a collection every half hour, with a total of 48 daily samples, graphed by the average of each day. It is found that the variable is not under statistical control, ie the frequency tends to go out of control at the upper limit.

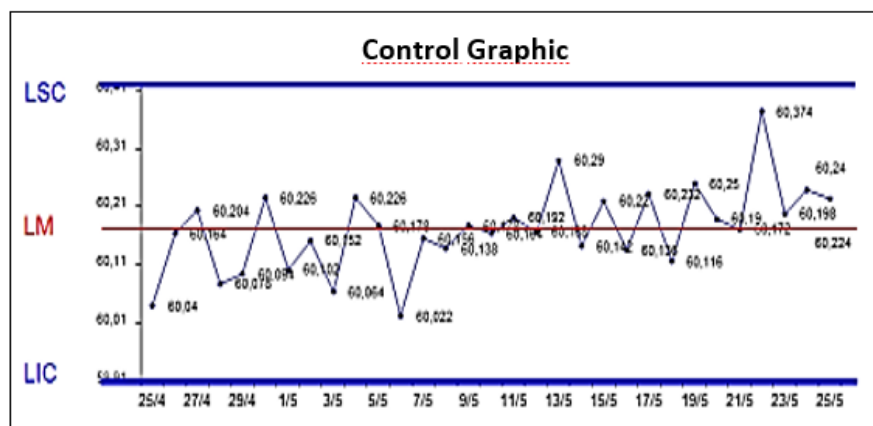

Figure 3: Amplitude graph of frequency behavior in Manaus. Source: [11].
The figure 4 shows that the frequency amplitude did not exceed the upper limits $(0.93 \mathrm{HZ})$ and had a slight tendency to exceed the lower limits, but did not get out of control. In addition to measuring the wave size, the equidistant oscillation between the points is verified, as it is not possible to verify this abnormality in the control mean.

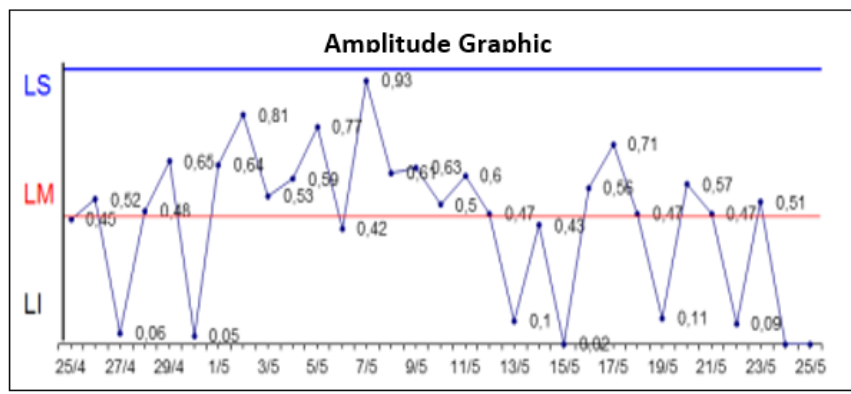

Figure 4: Amplitude graph of frequency behavior in Manaus. Source: [11]

\section{2 TENSION INSTABILITY IN THE MANAUS SYSTEM}

\section{2. 1 POWER FACTOR EFFECTS AND LEGISLATION}

Reactive power overloads generation equipment and the distribution network, limiting the ability to meet the active power demand. For this reason, the DNAEE, through Ordinance 1569 of

$12 / 23 / 93$, establishes that the consumers of electric energy keep the power factor of not less than 0.92 inductive from $6 \mathrm{~h} 30 \mathrm{~min}$ to $24 \mathrm{~h} 30 \mathrm{~min}$, and not less than 0.92 capacitive. from $12: 30$ am to 6:30 am Failure to observe this condition leads to the application of costly fines, presented on monthly energy bills. From the consumer's point of view, a low power factor means overload of transformers and cables, limiting their full utilization. Most loads in industrial and commercial installations produce inductive reactive power, such as motors, transformers and induction furnaces [2].

The flow of energy through the power grid consists of two distinct components:

- Active power is power that is effectively transformed into heat, light, mechanical work, or other uses. Its traffic in the system is unidirectional: from generation to consumer cargo. Represented by $\mathrm{P}$, its unit is $\mathrm{W}$ (or $\mathrm{kW}$ ).

- Reactive power that is temporarily stored in the electrical and magnetic fields of system equipment circulates pulsating between them. Its flow is bidirectional, coming and going with each cycle. Reactive power does not produce work or any other usable manifestation, and its presence is imposed by the characteristics of the charges, and may be inductive or capacitive. Its symbol is Q and its unit is var (or kvar) [12].

\section{2. 2 REACTIVE ENERGY FLOW}

Reactive electric energy is usually expressed in kVArh. By convention, when it is given in positive values it is inductive, and when negative it is capacitive. The opposite of inductive reactive energy is capacitive reactive energy, which is why it is expressed in the same unit, but with a negative value. Capacitive reactive energy is normally supplied to the electrical system by capacitors, [12].

Reactive energy is required for the operation of: induction electric motors, transformers, discharge lamps, induction furnaces, among others, are formed by charges that require an electromagnetic field for their operation. For the creation of this magnetic flux is the presence of reactive energy, which does not 
perform work. It circulates between the source and the load, taking up a "space" in the electrical system that could be used to provide more active energy. The active power loads that effectively performs work generating heat, light, motion, etc. It is measured in $\mathrm{KW}$ as illustrated in figure 5.

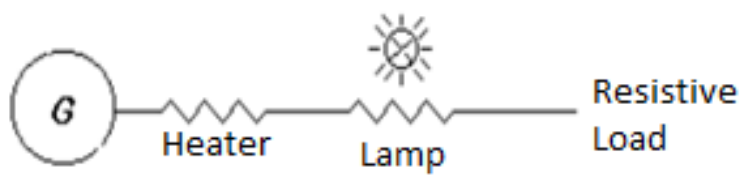

Figure 5: Active Power.

Source: [13].

Reactive power loads, power used only to create and maintain the electromagnetic fields of inductive loads. It is measured in KVAR as shown in figure 6.

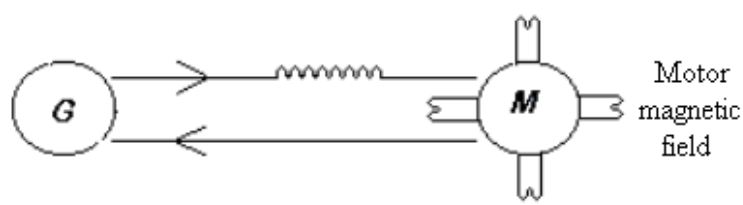

Figure 6: Reactive Power. Source: [13].

Figures 7 and 8 below show the situation of the Manaus system before the implementation of the new voltage control system through manual control of the power factor.

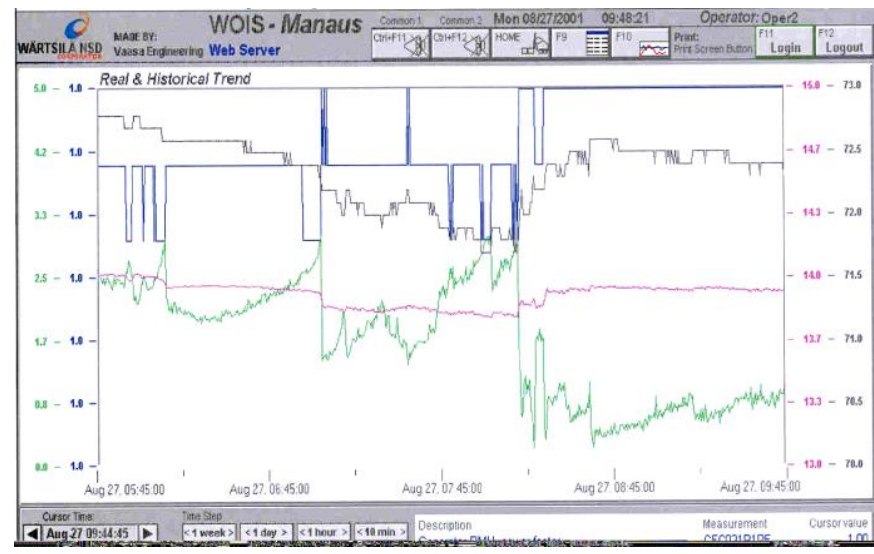

Figure 7: Voltage Unbalance vs. Reactive Power. Source: [11].

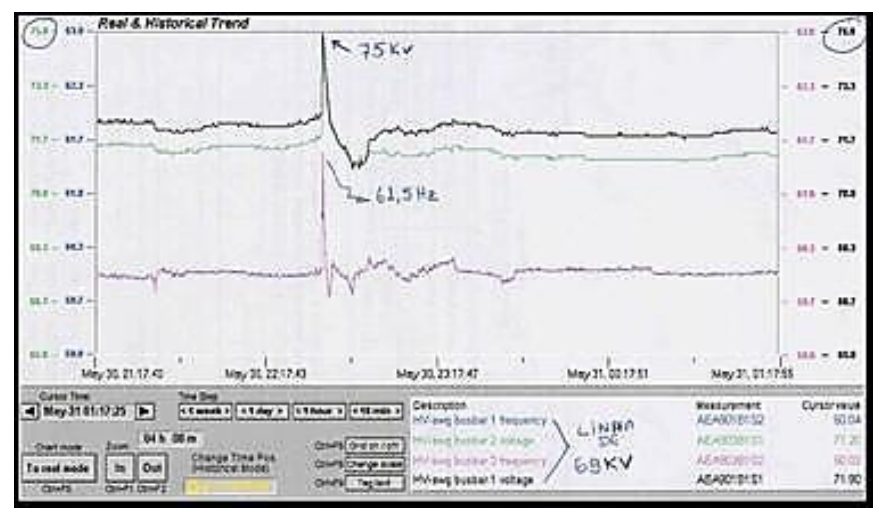

Figure 8: Effects of voltage instability (voltage oscillation). Source: [11]

\section{3 REAL TIME AUTOMATIC FREQUENCY CONTROL TECHNOLOGY}

The frequency is controlled through the electronic speed regulator - Woodward 723, which works in two modes: KW control and Speed Droop Control. KW Control is the mode of operation in which the machine is running with a constant load and the variations of load in the external system do not affect the value of the power in which the machine is working, it is as if the electric power had no variation. That is, in this mode of operation the Speed Regulator will not control or contribute to the frequency variations of the external System. Speed Droop Control, in this case the external system determines the System frequency, the machine being in parallel with other machines, and increasing or decreasing the reference speed will change the frequency. In Wartsila W46 technology the speed control is performed by Woodward Electronic 723 regulator (figure 08), the module has two inputs for magnetic speed sensors, which are installed to detect the passage of the flywheel teeth, the same provide voltage pulses of frequency corresponding to the machine's RPM, inputs are programmed so that readings are redundant, preventing possible sensor failures.

The WW-723 features a 20 to $200 \mathrm{~mA}$ analog output that acts directly on the hydraulic speed actuator to control fuel injection, increasing or decreasing machine speed to maintain its load-frequency ratio. The module also has a 4 to $20 \mathrm{~mA}$ analog input to read the active power being delivered by the generator to the system.

The speed regulator is programmed to maintain the machine's RPM so that the frequency stabilizes at $60 \mathrm{~Hz}$, under any load conditions imposed by the external system. This regulator has an analogue input of 4 to $20 \mathrm{~mA}$ so that the operator can supervise the operator. can increase or decrease the load on the system, and digital inputs to perform the same procedure manually, performed in emergencies or in manual synchronization of the machine with the bus, where the operator will need to adjust the electrical speed of the generator to to equalize the phase angle of the voltage with the phase angle of the bus voltage, for this maneuver the operator counts on the aid of the synchronoscope, which is the equipment in charge of comparing the phase voltage angle of the generator with that of the bus generating a visual signal at the moment the phase angles equal, giving the operator generator circuit breaker, thus completing the manual synchronization procedure of the machine.

\section{4 AUTOMATIC VOLTAGE CONTROL TECHNOLOGY}

Voltage control is performed by the Automatic Voltage Regulator (AVR). AVR operating modes are Voltage Droop and Power factor, whose operating mode settings are:

Voltage Droop: The external system determines the voltage, which once the voltage value is set the MVC (master voltage control), tracks the voltage on the high voltage side bar to minimize any fluctuations by sending the setpoint. and the signal $(\mathrm{mA})$ for each generator's PLC, which is converted to a voltage at the terminals of each AVR (Unitrol 1000) so that generators connected to the same bus share the reactive load, ensuring voltage control [14].

Power Factor: This is the mode of operation in which the machine is operating with a constant reactive load and variations in the external system load do not affect the value of the reactive power in which the machine is working. That is, in this mode of operation the Voltage Regulator will not control or contribute to voltage variations of the external System. The Machine Reactive Power value can be controlled by injecting more or less excitation 
current through the value of the power factor set on the PLC in the Control Room

The automatic voltage regulator (AVR) is responsible for maintaining constant voltage at the generator output terminals, it acts directly on the field excitation current, increasing or decreasing the magnetic field intensity, depending on the load characteristics at which Thus, we can say that loads with inductive characteristics tend to decrease the voltage, increasing or decreasing the intensity of the magnetic field, as a function of the characteristics of the load to which the system is subjected. Inductive loads tend to decrease the voltage at the generator terminals and capacitive loads tend to increase this voltage. Because these variations are inherent to the system, it is necessary to constantly change the generator excitation current by adjusting the power factor.

The UNITROL 1000 has an RS 232 serial port to communicate with other AVRs of machines working in parallel (figure 9):

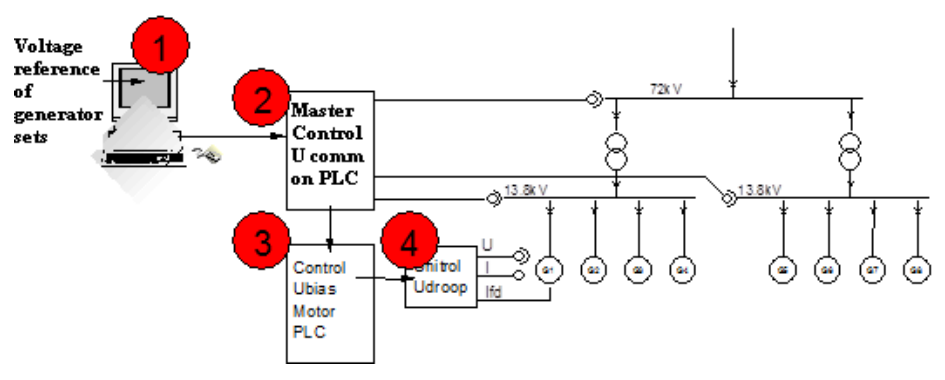

Figure 9: Circuit block diagram for voltage control. Source: [15].

Studying the diagram above it was observed that the Operator sets the voltage reference on the high voltage side, which in practice will be adjusted by Unitrol 1000. The new voltage control system makes it possible to run droop mode motors with an Automatic control (Voltage Control Master-CVM) voltage grid has been added.

Running in CVM mode means that the Reactive Energy will automatically be readjusted to keep the voltage grid at an adjusted level. Meaning that the Generated Energy Factor will fluctuate according to demand it may even be negative during some situations.

When stopping an engine in MVC mode, giving a stop command will start to unload the engine normally. The voltage mode will be changed to Power Factor mode and set to 1.0. This is done to minimize disturbance when an engine is to be shut down.

\section{RESULTS AND DISCUSSIONS}

\section{1 MANAUS PLANT TEST WITH NEW MODE OF OPERATION}

Considering the history of identifying difficulties in controlling the voltage and frequency of the electrical system in Manaus, even on a permanent basis and mainly after the startup of the Independent Energy Producers, a meeting was held in Brasilia involving the national company, the state company and independent producers, define an action plan involving the Areas of interest and affected by these difficulties in controlling that system.

Test tests were performed that generated the results described below according to the assumptions considered in the methodology:
- The Manaus Electric System generating units operate in automatic voltage and constant frequency control mode.

- The Manaus Electric System generating units allow operation with 0.9 inductive or capacitive power factor.

- The underfrequency protection setting on each generating unit is not more than $57 \mathrm{~Hz}$ and its time delay is not less than 600 milliseconds.

- The overfrequency protection setting on each generating unit is not less than $62 \mathrm{~Hz}$ and its timing is not less than 2 seconds.

- Criteria to consider are described below:

- The permanent regime statism of the generating units must be less than or equal to $6 \%$.

- Overshoot resulting from stepping on the RT of each generating unit must not exceed $5 \%$.

- RT time / response from generating units should not exceed 500 milliseconds.

Frequency variation in the Manaus Electric System should refer to ANSI / IEEE Guide C37.106 / 1987, in conjunction with C37.106-2003, as shown in Table 1, for underfrequency operation [16]:

Table 1: Event and Alarm Supervision Screen.

\begin{tabular}{|c|c|}
\hline FREQUENCY RANGE & LENGHT OF STAY \\
\hline $59,5 \mathrm{~Hz}$ a $60,00 \mathrm{~Hz}$ & CONTINUOUS \\
\hline $58,8 \mathrm{~Hz}$ a $59,50 \mathrm{~Hz}$ & 50 minutes \\
\hline $58,0 \mathrm{~Hz}$ a $58,80 \mathrm{~Hz}$ & 09 minutes \\
\hline $57,5 \mathrm{~Hz}$ a $58,00 \mathrm{~Hz}$ & 1,7 minutes \\
\hline $57,0 \mathrm{~Hz}$ a $57,50 \mathrm{~Hz}$ & 14 seconds \\
\hline $56,5 \mathrm{~Hz}$ a $57,00 \mathrm{~Hz}$ & 2,4 seconds \\
\hline Less than or equal to $56,5 \mathrm{~Hz}$ & 1,0 seconds \\
\hline
\end{tabular}

\section{2 IMPLEMENTATION AND TESTS PERFORMED IN VOLTAGE CONTROL MODE}

The tests to validate the voltage control mode of a generating unit consisted of applying 2 to 5\% steps in the voltage regulator reference of the unit under test and rejection of reactive power in unit in the electrical neighborhood of the unit under test, recording - voltage, reactive power, frequency, active power and field current in the unit under test. An observation test to validate the voltage control mode of a generating unit may be carried out by preselecting a reference voltage in the field and, in the electrical vicinity of the unit under test, to voluntarily reduce or increase the voltage by one unit. not exceeding $5 \%$ variation, sufficient to significantly vary the reactive power of absorption or supply in the unit under test, obeying the power factor of $0.9 \mathrm{pu}$, inductive or capacitive, and recording voltage, reactive power, frequency and active power in the unit under test.

\section{3 IMPLEMENTATION AND TESTING OF FREQUENCY CONTROL MODE}

The test to validate the frequency control mode of a subfrequency excursion generating unit consisted of rejecting in the field, in the electrical vicinity, another dispatching generator unit that voluntarily causes a change in the load - generation balance, sufficient to reduce (up to 1 Hertz maximum) system frequency, ensuring no load shedding by the ERAC (Regional Load Relief Scheme) or shutdown of any system generating unit by under frequency protection and recording voltage, reactive power, frequency and active power in the unit under test.

The test for validation of the frequency control mode of the generating unit with over-frequency excursion is to reject in the 
field the generating unit itself under test sufficient to significantly (up to $3 \mathrm{~Hz}$ maximum) increase the frequency empty terminal of the unit under test, ensuring no load shedding by the ERAC (Regional Load Relief Scheme) in the remaining system or shutdown of any remaining system generating unit by under frequency protection and recording voltage, reactive power, frequency and active power in the unit under test.

An impact test to validate the frequency control mode of an over frequency excursion generating unit consists of voluntary system separation on two stable islands, where possible and without load shedding, with active power interruption between future islands. That voluntarily cause a change in the load generation balance, sufficient to significantly increase (up to 1 Hertz maximum) the frequency of the island frequently, taking care that there is no load cut by the Regional Load Relief Scheme (ERAC). On the sub frequency island or generator unit shutdown on either island by sub-frequency or over-frequency protection and recording voltage, reactive power, frequency and active power on the unit under test.

Records to be obtained during the tests:

Voltage response test as a function of time

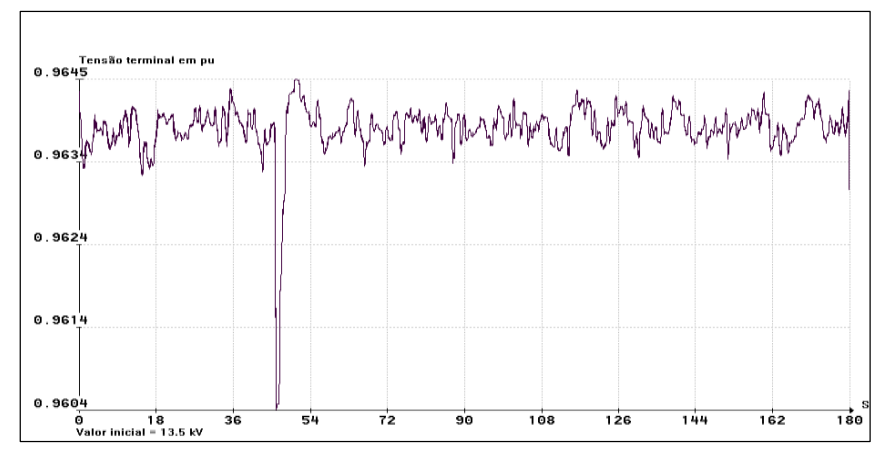

Figure 10: Graph of Voltage (pu) x Time (seconds) in Plant B unit 2.

Source: Authors, (2019).

This graph shows a maximum voltage deviation of $0.36 \%$ immediately after impact with response time less than 0.5 seconds and pre-impact voltage recovery by 2.9 seconds, with control accuracy less than $0.1 \%$, indicating operation in response mode. Constant voltage control adequately to the Manaus Electric System Operation. It is observed that the response time (less than 0.5 seconds) and stabilization time ( 2.9 seconds) were shorter than the reference time of 0.5 seconds and 5 seconds, respectively.

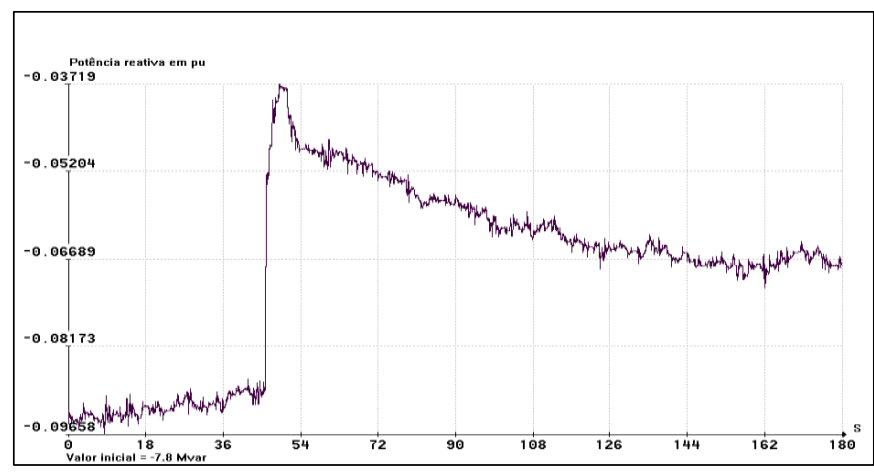

Figure 11: Reactive Power Graph (pu) x Time (seconds) in Unit 2 of Plant B.

Source: Authors, (2019).

The graph in figure 12 shows a maximum deviation of 2.34 Mvar in the reactive power of Plant B unit 2 from the initial value, reaching a deviation value with a stabilization trend of 1.0
Mvar, after 117 seconds of impact. Graph 12 shows the voltage droop operating mode validation test test on Wartsila motor technology at the Rio Negro plant.

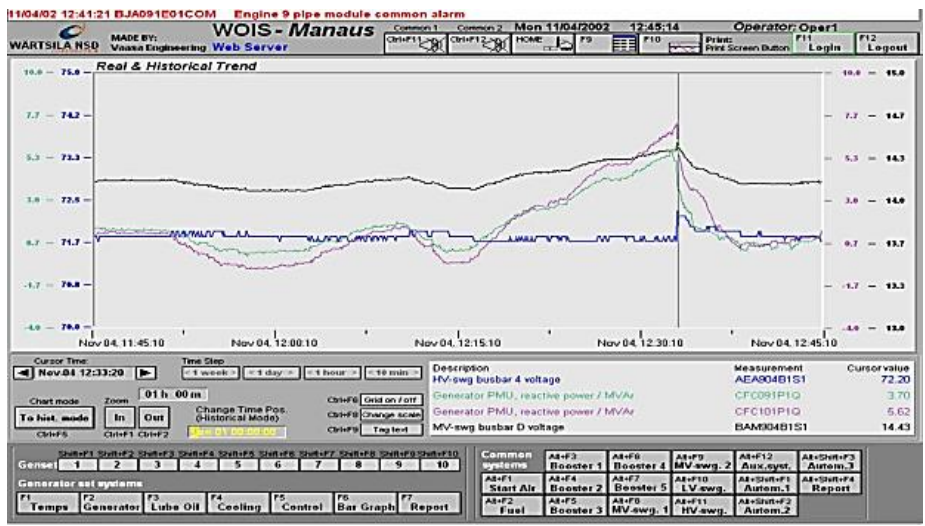

Figure 12: Reactive Response Assay.

Source: Authors, (2019).

In this example we observe a disturbance in the system such as the output of a machine that was generating reactive, and that machines 09 and 10 reacted and maintained the set voltage under control.

Frequency response test through load rejection.

Active Power Impact Test on a Plant W unit. This Test was performed by disconnecting Unit 2 Plant B with $40 \mathrm{MW}$, shown in Figure 13.

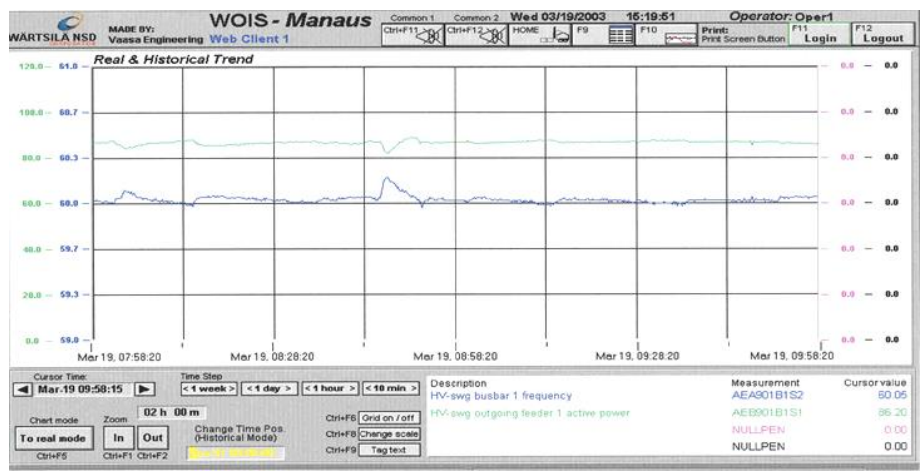

Figure 13: Frequency x Time graph (seconds) in W unit. Source: Authors, (2019).

This graph shows maximum frequency deviation in Plant W unit 2 from $0.80 \mathrm{~Hz}$ downward at 2.86 seconds after impact and frequency recovery trend from this moment on, with deviation stabilization at $0.48 \mathrm{~Hz}$, featuring automatic control mode operation. Constant frequency (load absorption). Speed droop test mode test with $16 \mathrm{MW}$ reject for validation as shown in figure 14 .

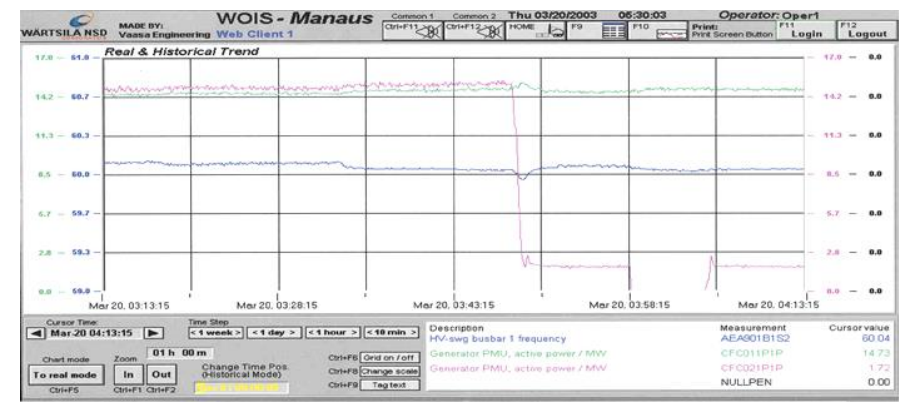

Figure 14: Active Power vs. Time Graph (seconds) in Plant $\mathrm{W}$ unit 2.

Source: Authors, (2019). 
This graph shows the maximum active power deviation in Plant B unit 2 of $16.4 \mathrm{MW}$, stabilizing the average deviation of 10.16 MW, characterizing operation mode in constant frequency automatic control with steady state statism of $5.3 \%$ considering power. rated at $67.5 \mathrm{MW}$.

\section{CONCLUSION}

It is concluded, therefore, that the methodology used in this process corresponded to the analyzes for performance evaluation and identification of the best Load, Frequency and Voltage Control strategies, when the Network Operation topology changes. It was found that the most appropriate strategy of Control Load, Frequency and Voltage for the case of the Manaus System was the replacement of discontinued technology equipment that worked with only one mode of operation. The Voltage Control and Woodward Load-Frequency Control Unitrol has been replaced by new modern Unitrol 1000 and Woodward 723 control equipment, which operate in two modes of operation: Unitrol 1000 which enabled the generators to operate beyond voltage control via the power factor, the automatic voltage control mode "Voltage droop" has now been implemented and a Master-CVM Voltage Control has been added to the high and medium voltage output bus. With MVC control, Generators connected to the same bus will share Reactive load quickly and efficiently, keeping the voltage level stable at the value determined by the operator. In the event of a sensor failure on the $69 \mathrm{kV}$ or $13.8 \mathrm{kV}$ output bus, the MVC is set to automatically change the operating mode and the system will be switched to Power Factor (PF) control mode. Woodward 723 electronic machine speed governor that operates with two modes of operation Speed Droop Control and KW control. For the case of the Manaus system the solution was to enable both control systems automatically with limited variation window, initially operates in KW Control mode and the external system determines the frequency of the System, and the Machine is in parallel with other Machines, and increasing or decreasing the reference speed will change the frequency and the system will change the operating mode to Speed Droop Control to make load-frequency correction shared between the generators. Speed control is performed by Woodward Electronic 723 regulator, the module has two inputs for magnetic speed sensors, which are installed to detect the passage of the flywheel teeth, and they provide voltage pulses of corresponding frequencies. At machine RPM, inputs are programmed so that readings are redundant, preventing possible sensor failures. At the end of the research, it was observed that the operation that meets all steady state load conditions and supports contingencies and disturbances, with minimum voltage and frequency deviation, fulfills the quality requirements of electric power supply, reducing frequency indices and duration of interruptions and providing higher revenues, thus representing the best strategy for load-frequency and voltage control when topology changes of the Manaus Operation Network occur.

\section{REFERENCES}

[1] Almeida, L. P. (2004). Performance analysis of Automatic Generation Control and Secondary Voltage Control. Rio de Janeiro: Federal University of Rio de Janeiro.

[2] ANEEL. Ordinance DNAEE no 1569, DE 23/12/1993. Available

in: https://sogi8.sogi.com.br/Arquivo/Modulo113.MRID109/Registro 35170/portaria\%20dnaee\%20n\%C2\%BA\%201.569,\%20de\%2023 -12-1993.pdf. Access in: of November 18, 2019.
[3] ANEEL. Annex to Resolution No. 505 of November 26, 2001. Available at: http://www.aneel.gov.br Accessed on 30 Sep. 2019.

[4] ANEEL. Agência Nacional de Energia Elétrica. Normative Resolution No. 583, October 22, 2013. Available at: http://www2.aneel.gov.br. Access on 30 Sep. 2019. (Replaces the Normative Resolution No. 407 of October 19, 2000 and 420 of November 30, 2010).

[5] ANEEL, Agência Nacional de Energia Elétrica. Automatic Generation Control Concept - CAG. 2019 Available at: http://www.aneel.gov.br. Accessed on 17 September 2019.

[6] ANEEL, Normative Resolution No. 414, of September 9, 2010. Available at: http://www2.aneel.gov.br Access on September 16, 2019.

[7] Caputo, G. A. S. (2009). A Transmission Expansion Planning Study in Power Systems Considering Uncertainty. Master's Dissertation in Electrical Engineering, Publication PPGENE.DM386/09, Department of Electrical Engineering, University of Brasilia, Brasilia, DF, 75p.

[8] Damasceno, Arnilson Jorge da Silva. Estimation of the potential for conservation of electricity in the residential sector of Manaus from the assessment of energy quality. Master Thesis Federal University of Amazonas. Manaus: 2012.

[9] Fernandes, P.C. Automatic Voltage Regulator: influence of gain on the electrical power system. Master Thesis Federal University of Itajubá: 2011, 86p. F363r.

[10] Ferreira, Carlos Aparecido; Costa, Vander Menengoy da. Continuous power flow voltage control: modeling and effects on voltage stability.

[11] Wartsila Technical consultancy. Operation Supervisory System 2019. Available at: http://www.wartsila.com. Consultation on September. 3, 2019.

[12] IEEE Guide for Frequency Protection for Power Generating Plants," in IEEE Std C37.106-2003 (Revision of

ANSI/IEEE C37.106-1987), vol., no., pp.0_1-34, 2004: 10.1109/IEEESTD.2004.94434. URL: http://ieeexplore.ieee.org/stamp/stamp.jsp?tp=\&arnumber=12705 $18 \&$ isnumber $=28449$.

[13] Haddad, Jamil. Energia Elétrica: Conceitos, Qualidade e Tarifação-. Rio de Janeiro, dezembro/2004. Available at:<http://www.mme.gov.br/documents/10584/1985241/Energ_El et_Conceitos_Qualid_Tarif_Ele tr_Procel-04.pdf $>$ Acesso em, v. 7,2004 .

[14] Gil, Antonio Carlos. How to design research projects. 5. ed. Atlas, Sao Paulo: 2010.

[15] POTÊNCIA ENGENHARIA - Electric Power Systems. Solutions for excitation and synchronization. Technical Advisory ABB Contact Center. Available at: http://www.abb.com. Access on Sep. 2, 2019.

[16] Kusko, Alexander; Fitzgerald, A. E.; JR Kingseley, Charles. Electric machines. McGraw-Hill of Brazil: 1975. 